\title{
INFORMAÇÃO E CENSURA NO BRASIL: DA FORMAÇÃO DO ESTADO À 'ERA DO REAL'
}

\author{
Véra Lucia C. OCTAVIANO' \\ Carla Monte REY ${ }^{2}$ \\ Kelly Cristina da SILVA ${ }^{3}$
}

\begin{abstract}
RESUMO
Rotineiramente, estudos realizados demonstram que buscar informações não se constitui hábito freqüente do brasileiro. O objetivo desta pesquisa foi coletar dados sobre a censura à informação que impera no país, desde a formação do Estado até a 'Era do Real' e nas constituições, enfocando o desempenho, fatores determinantes, formas como têm sido exercida e conseqüências nas práticas da leitura e da pesquisa.
\end{abstract}

Palavras-chave: Informação. Censura. Brasil.

\section{ABSTRACT}

In Brazil, studies on reading have showed that the Brazilian people rarely search information. This research aimed to collect data on the information censorship in Brazil since the Brazilian State formation until the "Real coin age $\mathrm{e}^{4 "}$, and in its constitutions. It focalizes censorship role, its determinant factors, the forms in which it has been applied, and its consequences on reading and research.

Keywords: Information. Censorship. Brazil.

INTRODUÇĀO

Apesar de o homem sempre ter se preocupado em documentar suas experiências, os fatos que vivencia ou lhe são narrados; ainda que busque informações das diferentes áreas do conhecimento humano; considerando que muitas idéias se originam de conhecimentos anteriores,

\footnotetext{
(1) Mestre em Biblioteconomia. Bibliotecária da EMBRAPA-CNPDIA, Caixa Posta 1741, CEP 13560-970 São Carlos, SP, Brasil, E-mail: vera@enpdia.embrapa.br

(2) Jornalista. EPTV Central, São Carlos, SP, Brasil

(3) Graduanda do Curso de Biblioteconomia e Ciência da Informação, UFSCar-DCI, Rod. Washington Luiz, km 235, Caixa Postal 676, CEP 13565-905 São Carlos, SP, Brasil,E-mail: kelly@cnpdia.embrapa.br

(4) Referência à moeda brasileira, o Real, oficializada pela segunda vez e cujo nome tem sido utilizado para caracterizar o período seguinte à sua vigência.
} 
a censura, velada ou não, tem acompanhado pari passu a informação desde sua geração, alcançando todos os seus suportes de veiculação.

Censura, ou qualquer outra denominação que se lhe atribua, é o instrumento utilizado para a manutenção de uma ideologia e, conseqüențemente, do próprio regime em vigor, o que explica o fato de a censura investir contra o que 'não está politicamente correto'.

Se o termo censura (do latim censere, que significa ter acesso), na Roma antiga designava os magistrados que procediam ao recenseamento, levantavam dados de indivíduos e propriedades, definiam direitos e deveres de cada classe social e eram árbitros sociais, podendo impedir a frequiência das pessoas a funções públicas e investigar suas vidas nos aspectos moral e familiar, hoje ele é tido mais como "um esforço por parte de um governo, organização, grupo ou indivíduo de evitar que as pessoas leiam, vejam ou ouçam o que pode ser considerado como perigoso ao governo ou prejudicial à moralidade pública" (Vergueiro, 1987, p.22).

A censura há muito tempo aparece como um problema. Entretanto, ainda não foi equacionada com objetividade. Há numerosos equívocos sobre essa questão, não no nível das posições - bem nitidamente definidas -, mas quanto à análise de sua lógica (Charbonneau,1985).

A literatura especializada não registra uma classificação para censura, porém ela tem emanado com caráter religioso, ideológico, cultural, ético, corporativo, tecnológico, público, político.

O pensamento do escritor Michel Foucault, exposto em sua obra História da sexualidade, foi resgatado pelo teólogo Padre Paul-Eugène Charbonneau. Para o escritor a censura age em três níveis, assume três formas principais, aplicadas a tudo que é objeto de censura: afirmar que uma coisa não é permitida, impedir que uma coisa seja dita, negar que uma coisa exista. Essas três formas, uma por vez, definem as manifestações da censura tal como é exercida (Charbonneau, 1985).

A forma mais corrente de censura é a mais elementar e menos sutil, aquela que implica em julgamento moral e tenta definir limites do comportamento humano. Nela os censores determinam os padrões de comportamento, as regras de agir do ser humano e interpretam à sua maneira. Essa censura é ineficaz, na medida em que nega o agir do homem, passando a ser um insulto ao próprio ser do homem (Charbonneau, 1985).

Dentre os veículos de comunicação da informação, a TV foi sempre a mais visada pela censura no Brasil. O veto de letras musicais, por exemplo, incluía rádio e $\mathrm{TV}$, enquanto eram liberadas para gravação em disco, execução em salas de espetáculos e reprodução em jornais e revistas. Esse procedimento se fundamentava no mito, até certo ponto baseado numa situação real, de que a TV adentra os lares, atinge indiscriminadamente a família e por isso precisava ser controlada (Gonçalves, 1986).

Muito embora, mesmo durante a ditadura, não tenha havido uma censura oficial sobre o conteúdo dos acervos das unidades informacionais brasileiras, a censura correu solta, trancafiando livros em armários/cofres, proibindo a aquisição de obras publicadas por editoras com visões de mundo diversas daquelas do regime vigente. Raramente alguém assumia a responsabilidade por essas medidas, em sua grande maioria ordens verbais ou telefônicas que ficavam sem registro (Vergueiro, 1986).

A fluência da informação, em nosso país, ainda permanece obstaculizada pela censura, muito embora, a partir da Nova República, o governo tenha aparentado tolerar maior liberdade. Exemplos disso recheiam as páginas de nossos jornais e revistas.

Sobre a questão censura $\mathrm{X}$ informação, a literatura especializada ainda é muito pequena, o que talvez explique o silêncio dos profissionais da área a esse respeito. Grande parte dos documentos se constitui de matérias publicadas em jornais e apresentam dados bibliográficos incompletos, são de difícil localização e recuperação para leitura.

O problema que envolve essa questão, no Brasil, começa na seleção de materiais que compõem os acervos das nossas unidades de informação, pela inexistência de uma política bemdefinida, que permita realizar essa tarefa sem a interferência de fatores subjetivos. Nos Estados Unidos, os profissionais da informação contam com a Library bill of rights e o apoio de sua 
poderosa associação de classe, a American Library Association (ALA), para orientá-los e lhes servir de guia.

Quantas unidades de informação brasileiras ainda sentem as ações da censura? E de que forma?

Os profissionais dessa área, certamente, muitas vezes estranham as dificuldades encontradas para pesquisar determinados assuntos. Os temas ligados à área tecnológica apresentam, realmente, obstáculos - os documentos mostram o desenvolvimento de uma pesquisa até determinado ponto e a partir daí o interessado tem que prosseguir sozinho -, alguns explicados pelo fato de a perspectiva do lucro geralmente estar por trás dessas pesquisas (Lucas, 1987; Cruz, 1994). Mas, e em outras áreas? Os profissionais brasileiros da informação - a quem cabe torná-la acessível - estão preparados para lidar com a censura? Sob que formas ela se apresentará nas próximas vezes?

\section{CENSURA E CONSTITUIÇŌES}

Levantamentos da inserção da censura nas constituições brasileiras mostram o seguinte quadro:

Constituição de 1891 (art.72, 12): a manifestação do pensamento é livre. Cada qual responderá por seus abusos, na forma da lei. Proíbe o anonimato. Constituição de 1934 (art.113, 9): mantém a liberdade de pensamento (exceto para espetáculos e diversões públicas) e ratifica os aspectos abusos e anonimato. Insere que livros e periódicos dispensam licença do poder público para publicação. Constituição de 1937 (art.122, inciso 15): permanece assegurada a livre manifestação do pensamento, oralmente, por escrito e de formas afins. A lei pode prescrever - quando precisar garantir a paz, a ordem e a segurança pública - a censura prévia da imprensa, do teatro, do cinematógrafo, da radiodifusão e, nesses casos, a autoridade competente pode proibir a circulação, a difusão ou a representação. A imprensa regular-se-á por lei especial, conforme princípios, e sua direção poderá ser exercida apenas por brasileiros natos. Constituição de 1946 (art.141, 5): livre manifestação do pensamento, com a ressalva incluída na de 1934 . Abusos e anonimato permanecem inalterados. Quanto a livros e periódicos, o texto repete a constituição de 1934 (Pontes de Miranda, 1947). Constituição de 1967 (art.153, 8): liberdade de pensamento, convicção política ou filosófica e prestação de informações, com a restrição aposta nas de 1934 e 1946. Sobre os abusos, repete o texto das constituições de 1891, 1934 e 1946. A publicação de livros, jornais e periódicos prescindem de licença da autoridade, porém, não serão toleradas as publicações e exteriorizações contrárias à moral e aos bons costumes (Brasil, 1987). Constituição de 1988 (art.5, IV): liberdade de manifestação do pensamento e proibição do anonimato; IX: livre expressão da atividade intelectual, artística, científica e de comunicação; XIV: o acesso à informação é assegurado a todos, resguardado o sigilo da fonte, quando necessário ao exercício profissional. Somente na vigência do estado de sítio é que poderão haver restrições ao sigilo das comunicações, à prestação de informações e à liberdade de imprensa, radiodifusão e televisão, na forma da lei (art.139, III); art.220, caput e 1: irrestrição para a manifestação do pensamento, a criação, a expressão e a informação, sob qualquer forma, processo e veículo (Brasil, 1988).

\section{CENSURA E ESTADO NOVO}

A formação do Estado brasileiro ocorreu com a proclamação da independência do Brasil.

Marx e Engels apresentam o Estado “... acima de tudo, como instrumento de dominação da classe dominante, ela própria definida em termos de detentora da propriedade e de controladora dos meios de produção" (Tavares, 1979, p.100).

Lénine (1980, p.227) caracteriza Estado como "...o órgão de dominação de uma determinada classe, que não pode ser conciliada com o seu antípoda (com a classe que lhe é oposta)..."

\section{CARACTERÍSTICAS DO ESTADO NOVO}

O Estado Novo, regime de exceção (1937-1945), possui como um de seus traços marcantes o fato de ter, pioneiramente, tentado dar um sentido mítico ao Estado (Carone, 1977). 
Apesar de seus líderes não terem atingido o nível e qualidades de chefes da nação, eles são mostrados como possuidores de personalidades e traços ímpares. Assim Getúlio Vargas é festejado a partir de seu aniversário de 19/4/1940, quando sua biografia e qualidades pessoais, tidas como invulgares, passam a ocupar páginas inteiras de jornais, atingindo o ápice em 1942, com a adesão de rádios, escolas, clubes, jornais, instituições profissionais e órgãos governamentais.

Idêntico processo é utilizado em favor de Darcy Vargas, esposa de Getúlio, e de seus colaboradores, como Adhemar de Barros, Osvaldo Aranha, Souza Costa, Goes Monteiro e Lourival Fontes.

\section{O DEPARTAMENTO DE IMPRENSA E PROPAGANDA (DIP)}

Fundado pelo Governo Provisório de 1930, o Departamento Oficial de Propaganda (1931) se transformou em Departamento de Propaganda e Difusão Cultural (1934) e em DIP (27/12/1939), subordinado diretamente ao Presidente da República.

O DIP teve como objetivos "....centralizar, coordenar, orientar e superintender a propaganda nacional, interna ou externa, e servir, permanentemente, como elemento auxiliar de informação dos ministérios e entidades públicas e privadas, na parte que interessa à propaganda nacional...", cabendo-lhe "...fazer censura de teatros e cinemas, estimular produção do cinema nacional, 'coordenar e incentivar as relações da imprensa com os Poderes Públicos', propaganda no exterior, proibir entrada de 'publicações estrangeiras nocivas aos interesses brasileiros', organizar programa de radio-difusão, etc," (Carone, 1977, p.171).

Inúmeras publicações de sua responsabilidade enalteciam a obra getulista, foram compradas pelos governos federal e estaduais e se espalharam pelo Brasil.

Foi de eficiência fundamental para divulgar a imagem do Estado, devido, em parte, ao seu diretor, Lourival Fontes, e ao poder que desfrutava, além do contexto próprio desse tipo de regime.

Suas Divisões de Divulgação, de Radiodifusão, de Cinema e Teatro, de Turismo e de Imprensa exerceram a censura em jornais, com censores nomeados para cada jornal. Quando de julgamentos, existia um Conselho Nacional de Imprensa (seis membros - três eleitos pelo Presidente da República e três nomeados pela Associação Brasileira de Imprensa e Sindicato dos Proprietários de Jornais e Revistas do Rio de Janeiro).

Cada Estado formou um Departamento Estadual de Imprensa e Propaganda (DEIP), com funções e obrigações análogas e subordinado ao do Rio de Janeiro. Como o DIP, os DEIPs faziam suas edições de livros e propaganda.

Com o tempo, o DIP passou a desenvolver a autopropaganda, homenageando seu diretor, Lourival Fontes, e seus sucessores (major Coelho dos Reis e capitão Amílcar Dutra de Menezes), o mesmo acontecendo com os dirigentes do DEIP de São Paulo (Cândido Motta Filho, Menotti Del Picchia e Cassiano Ricardo).

No Estado Novo, houve total censura dos jornais, sem quaisquer notícias contrárias ao governo. O rádio, grande instrumento de divulgação a partir da década de 30 , freqüentemente foi utilizado pelo DIP para levar aos lares as notícias oficiais. Foi criada a Hora do Brasil , com uma hora diária de duração, entre 19 e 20h., quando a maioria da população está em casa e recebe, assim, a informação padronizada ${ }^{5}$. Jornais Nacionais oficiais eram obrigatoriamente exibidos nos cinemas. Jornais, livros e folhetos também foram publicados e gratuitamente distribuídos pelo DIP, como mais uma forma de propaganda. Ocorreu, então, "...o desenvolvimento de um rígido modelo de exclusão cultural e política" (Mota, 1979, p.87), em um período de tensões externas (a Segunda Guerra Mundial) e internas (repressão política e inquietação cultural).

Marcaram o regime o autoritarismo e a compressão das liberdades civis sobre o clima

\footnotetext{
(5) Vale recordar que Hitler, por intermédio de Goebbels, também lançou mão de programa nesse mesmo estilo, veiculando as notícias do nacionalsocialismo com o objetivo de "...influenciar a opinião pública alemã, inclusive no ódio aos adversários e nos preconceitos raciais." (Martins, 1997, p. 1)
} 
intelectual; completa censura à imprensa; punições aos manifestantes da oposição; repressão e demissão dos não-ajustados à linha oficial; tribunais arbitrários e cárceres, como o Maria Zélia; censura e confisco de livros; interventores substituindo os organismos parlamentares, tudo em função da segurança do regime.

Os contatos com o exterior eram efetuados pelos viajantes em missões culturais e militares e pela $\mathrm{BBC}$, ouvida à noite.

No Rio de Janeiro, foi fundada a Associação Brasileira de Escritores (ABDE), responsável por sucessivas e sistemáticas críticas ao Estado Novo, juntamente com a Ordem dos Advogados do Brasil $(\mathrm{OAB})$ - que contava com Sobral Pinto, entre outros - e a União Nacional dos Estudantes (UNE), criada em 1937.

No período de 22 a 27 de janeiro de 1945, a ABDE promoveu o I Congresso Brasileiro de Escritores, em São Paulo-SP, na Biblioteca Municipal, no Centro do Professorado Paulista (CPP) e no Teatro Municipal. Esse congresso, aliado à repercussão do Manifesto dos Mineiros, foi um dos responsáveis pela queda do regime, devido à moção final de seus participantes (Mota, 1979).

Com a abertura democrática, o controle e a censura do DIP deixaram de existir (março de 1945), diante das críticas. Ele foi transformado em Departamento Nacional de Informações.

Todavia, os meios de comunicação particulares não foram automaticamente controlados com o golpe de Estado: as suas insatisfações foram vencidas por acordos, com o Estado Novo subsidiando jornais ou concedendo favores em papel; pela força, como a ocupação do jornalO Estado de S.Paulo(25/3/1939) ou algumas resistências subsistiram durante o regime, como o Diário de Notícias, do Rio de Janeiro, que lutou para conseguir as cotas de papel, fornecidas pelo DIP.

\section{O PODER MILITAR E A CENSURA}

Nesse período, instalado a partir do Golpe de Estado de abril de 1964 e vigente até 1978, o regime, em termos de censura, impôs uma forte repressão cultural.
A atividade intelectual que não estivesse sob a proteção ou o controle do Estado - seja jornalística, artística, científica - era enfrentada como suspeita, encarada sempre com intolerância ou mesmo reprimida sumariamente.

A censura de imprensa se justificava pelo perigo comunista que o comando de esquerda das redações representava para a democracia (Dimenstein, 1990).

Ianni (1978) explica essa política principalmente por dois motivos imediatos: 1) a atividade intelectual realizada independentemente do controle e da proteção do governo e, portanto, dos seus interesses, propunha interpretações e soluções diferentes daquelas aceitas e propaladas pelo governo para questões que o Estado encaminhava de modo contrário aos interesses da população (econômicas, políticas, culturais, educacionais e de saúde, entre outras). Para a realização de pesquisas sobre índios, por exemplo, havia necessidade de autorização da FUNAI, e sobre o operariado só se pesquisava com o apoio de um órgão público, além de temas que eram, praticamente, proibidos. Para o Estado a sua interpretação, monopolizada, bastava, não cabendo críticas, sugestões, debates e controvérsias e 2) a atividade intelectual, quando livremente exercida, faculta um clima de liberdade de informação, ensino, pesquisa, debate, controvérsia, o que o Estado não tolera.

Os centros universitários também sofreram a triagem policial, pesando sobre pesquisadores, alunos e professores inquérito policial, ameaça de aposentadoria e até mesmo prisão.

Por disposições do AI-5 (13/12/1968), o Presidente da República podia decretar o recesso do Congresso Nacional, das Assembléias Legislativas e Câmaras de Vereadores, por Ato Complementar, em estado de sítio ou não, voltando a funcionar quando por ele convocados; durante esse recesso, o Poder Executivo correspondente estava autorizado a legislar em todas as matérias e exercer as atribuições previstas nas constituições ou na Lei Orgânica dos Municípios; para preservar a Revolução o Presidente da República, após ouvir o Conselho de Segurança Nacional e sem as limitações previstas na Constituição, podia suspender os direitos políticos dos cidadãos por 10 
anos e cassar mandatos eletivos federais, estaduais e municipais. O Decreto-Lei no 477 (26/2/1969), apoiado no AI-5, previa punições para professores, alunos e funcionários de estabelecimentos de ensino que cometessem infrações disciplinares (Ianni, 1978).

A atividade intelectual foi classificada como um mau exemplo e um perigoso precedente para os demais setores da população, por seu exercício não se restringir aos muros dos centros universitários.

Entre 1964 e 1978, todavia, o Estado não se manteve exatamente o mesmo. Sucederam-se na Presidência o Marechal Humberto de Alencar Castello Branco (1964-1967) e os Generais Arthur da Costa e Silva (1967-1969), Emílio Garrastazu Médici (1969-1974), Ernesto Geisel (1974-1979) e João Baptista de Oliveira Figueiredo (1979-1984).

Cada governante tem seu estilo pessoal. Em termos de organização da cultura, porém, os governos não apresentaram grandes alterações.

No Rio de Janeiro (1965), houve apreensão do livro História nova do Brasil e prisão de seus autores (Nelson Werneck Sodré, Maurício Marins de Melo, Pedro de Alcântara Figueira e Joel Rufino dos Santos), mediante portarias dos Ministros da Educação e Cultura e da Justiça, sob a alegação de que a história brasileira estava sendo contada de forma sectária, subversiva e desvirtuada (Ianni, 1978).

A cantora Maria Bethânia, em 1971, recebeu 9 censores, todos sentados na primeira fila, no ensaio geral de seu show Rosa dos Ventos, no Teatro da Praia, Rio de Janeiro (Sanches, 1997).

Em novembro de 1971, o jornalista cearense Freitas Nobre, vice-líder do PMDB, denunciou a existência de censura prévia em certos órgãos, com matérias revisadas pessoalmente pelo censor ou através de comunicações verbais telefônicas, baseado em relatórios e documentos divulgados pela Associação Interamericana de Imprensa (Censura..., 1971).

Em 1973, discurso do PMDB (oposição) não foi ao ar (O discurso..., 1973). Em 1976, a publicação prevista para 4/7, no jornalMovimento (São Paulo), da Declaração de Independência dos Estados Unidos, em homenagem ao Bicentenário de Independência desse país, foi vetada (Censura...,
1976). Em 1978, houve o fim da censura prévia aos jornais Movimento (São Paulo), sob censura por três anos, desde o primeiro número, Tribuna de Imprensa (Rio de Janeiro) e O São Paulo (da arquidiocese paulista), dentro da abertura política gradual conduzida pelo Presidente Geisel (Ludwig..., 1978). 298 ordens de censura haviam sido expedidas contra jornais. Até uma edição especial em comemoração ao Dia Internacional da Mulher, abordando seu papel no Brasil, suas atividades, a dupla exploração que sofrem, na casa e no trabalho, foi cancelada pelo jornalMovimento, devido à censura vetar 337 laudas de texto e 65 ilustrações, mais de $80 \%$ do material. Esse jornal também teve fotos, a charge, o humor vetados em todos os anos em que a censura esteve lá (Três..., 1978).

Apesar do fim da censura prévia a esses três jornais, em 1978 o Governo Federal através de seus órgãos da área econômica (Ministério da Fazenda, Indústria e Comércio, Planejamento e o Banco Central) continuou sonegando informações estatísticas precisas sobre a situação das empresas multinacionais no Brasil, processo iniciado em 1974 (Loureiro, 1978).

No início de 1979, atendendo a pedido do Ministério da Justiça, cujo ministro era Armando Falcão, o procurador Vaillati Filho, da $2^{\mathrm{a}}$ Auditoria Militar, acrescentou novas acusações às denúncias anteriores contra o jornalista Antonio Carlos Carvalho Ferreira, diretor responsável do jornal Movimento. O coronel Erasmo Dias, quase ao mesmo tempo, abriu processos contra vários jornalistas do Repórter, do Rio de Janeiro (O governo..., 1979).

Ignacio de Loyola Brandão teve seu livro Zero apreendido, o mesmo acontecendo a Renato Tapajós com Em câmara lenta. Incluem-se, também, outros escritores, como Rubem Fonseca, José Louzeiro e as sempre censuradas, por pornografia, Cassandra Rios, Adelaide Carraro e Brigitte Bijou. Foram, também, vetados filmes, peças teatrais (entre elas $O$ rei morreu, viva o rei, de Cesar Ladeira) e letras de músicas populares, inclusive um samba-enredo da Escola de Samba Unidos do Cruzeiro, do Rio de Janeiro, por citar o nome de Juscelino Kubitschek entre os fundadores de Brasília. A cantora Maria Alcina também foi 
suspensa, em nome da moral e dos bons costumes. Em 6 de julho de 1978, o ministro Falcão censurou 12 obras eróticas, o que ocupou duas páginas do Diário Oficial da União. Esse ministro, entre 1974-1979, proibiu mais de 400 livros, 117 peças teatrais, 47 filmes, 840 letras musicais. Ele deu seu nome à lei que proibiu o uso do rádio e da TV nas campanhas eleitorais (Censura..., 1979).

Curitiba-PR (março de 1978) teve diretores e professores de escolas pré-primárias (Oca e Oficina) presos, sob a acusação de ensinarem marxismo aos alunos de 2 a 6 anos de idade. Essas escolas se baseavam nos ensinamentos de Jean Piaget.

O Estado era o juiz da atividade cultural; a ele cabia estipular o certo e o errado, o permitido e o proibido.

Durante os 14 anos de regime militar, dezenas de publicações não conseguiram sobreviver, pois a censura provocava a diminuição de documentos e queda das vendas nas bancas (Três..., 1978).

O rádio e a televisão não podiam registrar o que acontecia no país; tão-somente divulgavam o que o governo quisesse. Podia-se, por exemplo, falar sobre o esquadrão da morte, desde que de forma a parecer algo misterioso, sem origem, mágico.

A partir de 1964, a questão universitária foi transformada pelo governo em questão de polícia (Ianni, 1978). A Universidade de Brasília (UnB) teve seu campus cotidianamente visitado pela polícia, em 1977, ano em que também houve invasão e depredação de prédios e material didático da PUC-SP, com bombas e prisões para estudantes.

O boato igualmente foi usado como forma de intimidar, gerar medo e insegurança, confundir, a ponto de o líder sindical Luís Inácio da Silva, em sua posse (abril de 1978) dizer que chegara o momento de "começarmos a exigir das autoridades e dos empresários o direito de não termos medo." (Ianni, 1978, p.225).

Além dos boatos, houve mortes, como as do professor e jornalista Vladimir Herzog e do político cassado Rubens Paiva, dentre as mais conhecidas.

Após os acordos MEC/USAID (1965-1968), o sistema educacional (público e privado) sofreu modificações, visando a adequá-lo à doutrina políti- co-econômica do Estado, qual seja, a formação de cidadãos dependentes e acríticos (Ianni, 1978).

A censura também era adotada como técnica de controle ou repressão cultural, ao lado de órgãos do MEC reformulados, como: Conselho Federal de Cultura, Conselho Federal de Educação, Serviço Nacional de Teatro, Empresa Brasileira de Filmes, Comissão Nacional de Moral e Civismo, Fundação Nacional de Arte e vários outros.

Direta ou indireta, aberta ou velada, discreta ou agressiva, a censura esteve presente no cotidiano de jornalistas, editores, artistas, professores e pesquisadores. Entre janeiro e dezembro de 1974, os funcionários da Rádio Globo do Rio de Janeiro anotaram 111 chamadas telefônicas da Polícia Federal (Microfones..., 1979). No início de 1980, foi aberto Inquérito Policial Militar contra o Coojornal, órgão da Cooperativa dos Jornalistas de Porto Alegre, pela divulgação, em sua edição de fevereiro desse mesmo ano, de um relatório secreto do exército brasileiro sobre o combate ao movimento guerrilheiro de Carlos Lamarca no interior dos estados de São Paulo e Bahia entre 1970 e 1971 (É crime..., 1980). Em agosto de 1980, a União foi condenada a indenizar os jornais $O$ Estado de S.Paulo e Jornal da Tarde pela censura prévia às edições de 10 e 11 de maio de 1973, cujas notícias se referiam à demissão do ex-ministro da Agricultura Luís Fernando Cirne Lima (Vitória..., 1980).

A censura oficial, exercida pelo Departamento de Polícia Federal, nem sempre apareceu sob a forma de proibição ostensiva ou da ação policial. A reunião anual da SBPC de 1977 aconteceria no campus universitário de Fortaleza. Segundo um boato, era inviável sua efetivação ali e ela foi realizada na PUC-SP. Sabe-se que, de Brasília, partiu a notícia de que a participação dos funcionários públicos fora vetada pelo governo federal e proibido qualquer tipo de auxílio material dos ministérios e empresas públicas ao evento. Os Ministros de Estado receberam ofício nesse sentido, proveniente dos órgãos de segurança, e repassaram as recomendações às divisões de segurança e informações dos organismos estatais. Os que se intimidaram não compareceram; os que participaram o fizeram receosos do que lhes poderia acontecer (Ianni, 1978). 
E A CENSURA NA 'NOVA REPÚBLICA', NO 'BRASIL NOVO' E NA 'ERA DO REAL'?

Oficialmente, a censura terminou, no Brasil, em 1978 (A Imprensa..., 1997).

Extinto o AI-5, a censura política começou a se distanciar dos programas jornalísticos do rádio e TV.

Quando o general Ernesto Geisel passou a presidência da república ao general João Baptista Figueiredo (15/3/1979), nenhum órgão de comunicação social no Brasil estava sob censura oficial (Fui..., 1985).

Porém ... Mansamente, sem que o público percebesse, a censura do Governo Federal voltou e vetou duas peças e três filmes (dentre eles a peça Não seria o Arco do Triunfo um monumento ao pau-de-arara?, do jornalista Licínio Rios Neto, sobre a vida do Frei Tito). O último veto integral a uma peça havia ocorrido em 1977, A patética, de João Ribeiro Chaves Neto (Caballero, 1984).

Solange Maria Teixeira Hernandes, Chefe da Divisão de Censura de Diversões Públicas (DCDP), desde 1982 corta filmes, proíbe peças de teatro e muda capítulo de telenovelas (Fantini, 1984).

Até missa foi proibida. Em 1981, Vivaldo Patrocínio dos Santos foi obrigado, pelo governador baiano Antonio Carlos Magalhães, a desmarcar a missa de $90^{\circ}$ dia pela morte de seu filho Valmir Alcântara, tenente assassinado por fuzileiros navais durante a greve da Polícia Militar baiana de março desse ano (Missa..., 1981).

Em abril de 1982, o presidente Figueiredo pediu ao ministro da Educação Rubem Ludwig que demitisse o diplomata Celso Amorim, presidente da Embrafilme desde 1979. Na mesma tarde Amorim se exonerou. Ele caiu sob o peso da reação militar ao filme Pra frente Brasil, que financiara (Um nervo..., 1982).

Em abril de 1983, o jornalista Guilherme Costa Manso, da revista Veja, teve sua credencial retirada por ter escrito uma reportagem sobre o lixo das residências oficiais da Península dos Ministros, em Brasília, DF, sob o título $O$ que o poder devolve (Lixo..., 1983).

Em 1984, o Ministério da Justiça elaborou anteprojeto de lei sobre censura, considerado por profissionais ligados às artes ou entidades de classe mais restritivo do que aquele em vigor (Caballero, 1984). Alterações foram feitas em sua versão final. O ministro da Justiça Ibrahim Abi-Ackel impediu a publicação, no Diário Oficial da União, dos estatutos do PCB enviados pelo Departamento de Imprensa Nacional para a organização provisória do partido (Ackel..., 1984; Galvez, 1984b). Em abril, a TV Globo e a Rede Manchete também tiveram problemas com a censura em seus noticiários, bem como os programas de rádio e TV (noticiosos, jornalísticos, de debates, entrevistas e pronunciamentos) produzidos ou gerados em Brasília e nos 10 municípios goianos submetidos a medidas de emergência, os quais dependiam de censura prévia do Departamento Nacional de Telecomunicações, o Dentel (Censores..., 1984). Ainda nesse abril, no seu primeiro dia de trabalho, o Dentel deteve, durante quase uma hora, os fotógrafos Jorge Araújo (Folha de S.Paulo), Antonio Dorgivan (Jornal do Brasil) e Kim-Ir-Sen (Agência Ágil). Não os entregou à Polícia Militar porque eles aceitaram entregar os filmes contendo fotos da sala onde o Dentel executava a censura às telecomunicações (Galvez, 1984a). Em maio, o personagem o Porta-voz não apareceu no Viva o Gordo, programa humorístico da Rede Globo comandado por Jô Soares. A emissora afirmou ter sido decisão interna. Novelas como Partido alto e Transas e caretas tiveram diálogos sistematicamente suprimidos (Fora..., 1984).

Em maio de 1985, a liberdade ainda não havia chegado ao Ministério da Previdência Social. Carlos Meireles, chefe de gabinete do ministro Waldir Pires, fechou pessoalmente a porta na cara dos repórteres que queriam entrevistar o chefe do Serviço Nacional de Informações (SNI), general Ivan Souza Mendes, que viera propor ao chefe de gabinete uma estratégia para combater fraudes hospitalares que já ultrapassavam $\mathrm{Cr} \$ 1$ trilhão (Ministério..., 1985). Em outubro, a novela Roque Santeiro, do teatrólogo Dias Gomes, sofreu cortes da Censura Federal em Brasília, em vários capítulos que inseriam cenas de infidelidade conjugal explícita. Para o seu autor, "a Nova República é uma velha que fez plástica." (Censura..., 1985). Ela havia sido vetada pelo ministro Armando Falcão no governo Geisel (Fui..., 1985). 
A Nova República também teve uma ideologia. Assim, necessitou preservá-la, mantê-la para se manter.

“...os tempos são outros, a Nova República acabou com todos os tipos de censura e as bibliotecas não mais sofrem pressões para colocar quaisquer obras fora do alcance de seus usuários. Será? Terão as asas da liberdade finalmente se aberto sobre nós? Nem tanto assim" (Vergueiro, 1986, p.2).

Sob a presidência do escritor José Sarney (1986-1990), atualmente membro da Academia Brasileira de Letras, o país viveu sob o regime de censura política (inexistente desde o governo de Geisel e até Figueiredo, que saiu em 15/3/1985). Ele ordenou a proibição da retransmissão de uma entrevista do governador Leonel Brizola, de responsabilidade do ministro Antonio Carlos Magalhães, uma de Darcy Ribeiro e um programa jornalístico e diário da TVE, cuja retransmissão foi proibida em Brasília, pois a independência dos jornalistas desse programa não é aceita pelo poder (Freitas, 1986).

A Comissão Provisória de Estudos Constitucionais de seu governo elaborou um anteprojeto de medidas a serem adotadas durante o estado de sítio, que previa impedimentos à divulgação de informações por rádios, jornais e TV sob o argumento de que veicular irrestritamente notícias em tais ocasiões constitui um risco à segurança nacional (Plenária..., 1986; Volta..., 1986).

Em 26 de junho de 1986, livros comoDiário de Che Guevara na Bolívia, $O$ último tango em Paris, O livro vermelho de Mao Tsé-Tung e Octobre 72, pensamento político de Allende, além de revistas, folhetos e documentos da UNE, foram encontrados em um cofre-forte da Biblioteca da UnB, por seu diretor Murilo Bastos Cunha, que afirmou não poder precisar quando o fato ocorreu. Junto a esse material, estavam 27 medalhinhas com a efígie de Mao Tsé-Tung, em um envelope com a inscrição: medalhinhas subversivas. Bastos Cunha declarou que os dizeres da inscrição elucidavam os motivos: eram consideradas material subversivo. O Jornal de Brasília (27/6/1986)noticiou que o reitor da UnB no período de 1974-1985, capitão-de-mar-e-guerra
José Carlos de Azevedo, foi quem ordenou a guarda dos materiais. O ex-reitor refutou a acusação, afirmando que havia dois cofres na UnB: um manipulado pelo diretor da Biblioteca; outro, pelo tesoureiro (Cofre..., 1986).

Quanto à ação do governo, um dos primeiros e mais debatidos atos de censura da Nova República foi a retirada do filme Je vous salue Marie, de Jean-Luc Godard, das telas dos nossos cinemas.

Em São Paulo, o Prefeito Municipal, Jânio da Silva Quadros, através do Ofício Circular 21/86, da Secretaria do Governo Municipal, proibiu a renovação de assinatura, na Prefeitura, das revistas Veja, Isto É e Senhor e do jornal Diário Popular. E a imprensa, falada ou escrita, não divulgou uma palavra sequer sobre o assunto, assim como os bibliotecários e usuários das bibliotecas afetadas (Vergueiro, 1986).

$\mathrm{Na}$ disputa presidencial de 1989 , os adversários políticos Collor e Lula, Brizola e Maluf bombardearam o jornal Folha de S.Paulo com processos e acusações: cada um alegava que se sentia perseguido pelo jornal, a serviço do oponente (Dimenstein, 1990).

Na Era Collor, os meios de comunicação noticiaram que o presidente Collor de Mello julgava que certos programas eram impróprios para a televisão, por atentarem contra a moral e os bons costumes do povo brasileiro. Divulgaram, também, que a Rede Globo proibiu palavrões e cenas de sexo nas novelas que veicula até as $22 \mathrm{~h}$., numa tentativa, talvez, de se antecipar a uma possível censura prévia instituída.

Também tiveram grande repercussão nacional, com severas contestações, os episódios relativos ao jornal Folha de S.Paulo, como sua invasão por agentes da polícia federal; o processo movido em agosto de 1990 pelo governo Collor, com base na Lei de Imprensa (1967), em que o jornal foi acusado de calúnia, devido a reportagens publicadas entre $27 / 7$ e 2/8/1990 sobre contratos de publicidade efetuados pelo governo federal sem licitação e a carta-aberta do seu diretor de redação, Otavio Frias Filho, classificando a ação como tentativa de intimidar a imprensa brasileira (Dimenstein, 1990; Jornalistas..., 1991). Além desse jornalista, Josias de Souza (diretor-executivo da sucursal 
de Brasília) e os repórteres Nelson Blecher e Gustavo Krieger depuseram dia 1/3/1991, na $4^{\mathrm{a}}$ Vara de Justiça Federal Criminal de São Paulo, ante o juiz João Carlos da Rocha Mattos e na presença da procuradora da República Lúcia Helena Rosas de Ávila Feijó (Folha..., 1991).

Não é raro que repórteres tenham suas cabeças pedidas por governantes. Dimenstein (1990, p.154) afirma, inclusive, que "Quando o poder e a imprensa se dão muito bem, o leitor se dá mal."

Em novembro de 1992, a Câmara Especial do Tribunal de Justiça de São Paulo reformou sentença que determinava lacre diário no jornal Notícias Populares, atribuindo a seus editores a responsabilidade pelo conteúdo do jornal ('NP' recorre..., 1993).

Recentemente, a justiça determinou censura prévia contra esse mesmo jornal. Visava impedir que ele prosseguisse com série sobre a vida e a obra do cantor Roberto Carlos. Em que pese a polêmica proteção aos direitos da personalidade, a liberdade à informação foi tolhida (Dotti, 1993a), ainda que Etcheverry (1997) saliente que a liberdade de imprensa encontra seu limite no ponto em que, se exercida, viole o direito alheio.

Jornalistas que lutam contra essa censura têm sido acusados de falta de ética profissional pelos advogados da vítima, em um novo tipo de censura prévia (Dotti, 1993b). Cabe ressaltar que, apesar de abordarem as liberdades intelectual, artística, científica e de comunicação, a constituição e a lei ordinária brasileiras não estabelecem limites entre liberdade de informação e direitos da personalidade.

$\mathrm{Na}$ atividade jurisdicional, os juízes têm se defrontado com práticas abusivas de empresas de comunicações, enquanto os tribunais hesitam frente à possibilidade de matéria jornalística ser submetida à avaliação prévia (Pereira, 1997).

O Brasil, na Era do Real, mudou sua moeda não a face desta, que continua voltada para o lado que estampa a censura.

Em 16 de junho de 1997, o jornal Zero Hora, de Porto Alegre-RS, publicou a lista dos 200 funcionários públicos mais bem pagos desse Estado. Vinte e dois auditores do Tribunal de Contas não gostaram, impetraram mandado de segurança pedindo que o governo estadual fosse proibido de fornecer seus nomes e salários e que esse jornal os divulgasse. Medida liminar concedida, Zero Hora censurado durante seis dias (A Imprensa..., 1997).

Ecomo no episódio da proibição de renovação de assinatura de revistas e jornais na Prefeitura de São Paulo, por Jânio Quadros, anteriormente citado, a imprensa nacional "fez de conta que não era com ela" (A imprensa..., 1997, p.1-2).

O projeto da Lei de Imprensa brasileira, em discussão na Câmara dos Deputados, vem sendo objeto de críticas. No jornal $O$ Estado de S. Paulo de 13/5/1997, Paulo Cabral, presidente da Associação Nacional de Jornais, acusa-a de ser uma censura prévia de ordem econômica por prever pena de prisão para jornalistas condenados por calúnia, injúria, difamação, e pelo valor do teto para as indenizações resultantes das condenações (20\% do faturamento da empresa jornalística, o que poderia quebrá-la). Américo Antunes, presidente da Federação dos Jornalistas, alerta que a nova Lei poderia criar uma autocensura no jornalista, que não apostaria em reportagens que pudessem trazer conseqüências (A imprensa..., 1997).

Em Manifesto à Nação de 5/10/1997, publicado na primeira página do jornal Folha de S.Paulo sob o título Ameaça à liberdade de imprensa, a Associação Nacional de Jornais (ANJ), a Associação Nacional de Editores de Revistas (ANER), a Associação Brasileira de Emissoras de Rádio e Televisão (ABERT) e a Associação Brasileira de Imprensa (ABI) denunciam que esse projeto, se aprovado, ameaça a liberdade de expressão no Brasil. Para elas, "Trata-se da maior ameaça que a livre circulação de idéias e informações sofre desde o regime militar”. Por não limitar o valor das indenizações financeiras por calúnia, injúria e difamação, poderão ocorrer condenações desproporcionais ao dano causado, fechamento de empresas jornalísticas. Além disso, propõe multa de até $\mathrm{R} \$ 100$ mil contra jornalistas (podendo provocar a volta da autocensura nas redações) e permite apreensão de jornais e revistas.

É interessante observar que, enquanto um jornal ou um jornalista pode ser punido por falsear informações, inexiste um instrumento legal que puna os que passam informações falseadas à 
imprensa (Moraes, 1996). Também há que se considerar que um dos direitos humanos fundamentais é o direito à privacidade e à intimidade. Ainda que indenizações sejam previstas, “... mais justo do que indenizar é prevenir.” (LEITE, p.10).

\section{CONSIDERAÇŌES FINAIS}

Quantos profissionais de imprensa já não tiveram suas matérias cortadas, vetadas, desfiguradas, por interesses muitas vezes sequer claramente identificados? Quantos foram punidos, demitidos, perseguidos por publicarem o que não deviam? Quem já não recebeu uma ameaçazinha (velada ou explícita) em relação à publicação ou não de um determinado tema? Em quantas reuniões de pauta alguns assuntos políticos foram considerados perigosos, desaconselháveis? (Pelúcio, 1997).

O próprio direito concedido a emissoras de televisão para transmissão exclusiva de eventos esportivos, carnavalescos e tantos outros de caráter nitidamente popular, já se configura como uma forma de censura, de vez que tolhe a liberdade de escolha ou mesmo de acesso dos indivíduos (quando a emissora privilegiada não é transmitida para a cidade em que se mora). Além disso, o detentor da exclusividade não é o dono dos artistas do espetáculo e não os mantém - já não é o caso de novelas, seriados, programas de auditório e outros que tais. Essa é uma maneira interessante, e no mínimo curiosa, de censura, de vez que o censor não detém poder algum sobre o objeto censurado (ou exclusivo).

Nas unidades de informação, a tarefa de selecionar os materiais bibliográficos requer cuidados especiais, pois seus executores devem ter sempre presente que o público é heterogêneo, ainda que possa convergir mais para a área predominante no seu acervo. O problema é ainda mais complexo porque a abrangência dos assuntos é imensa. Alia-se a isso o fato de que a dita 'mentalidade' das pessoas muda com as gerações: os bons costumes de 1920, hoje podem não ser considerados tão bons. E muitos, certamente, já não são.

O próprio BID impediu por décadas que, com seus recursos, bibliotecas - unidades de informação por excelência - e organismos afins adquirissem livros e títulos de periódicos publicados nos países não-alinhados, quais sejam, os não-membros do BID, sob a justificativa de serem publicados em países não-elegíveis.

Ainda que a censura não intervenha na seleção, esses profissionais precisam se manter vigilantes. Asheim (1980, p.220-221) alerta para problemas que poderão surgir para os bibliotecários brasileiros e que já estão sendo enfrentados pelos norte-americanos: "Como evitar a acusação de que por sua falha profissional o bibliotecário torna-se o censor?".

Para Vergueiro (1986, p.3), não há meio termo: quando as bibliotecas deixam de apresentar em seus acervos todos os pontos de vista sobre os assuntos por elas cobertos, o bibliotecário está exercendo o papel de ajudante dos censores, sejam de direita ou de esquerda.

De qualquer modo, convém que se tenha presente, e de forma sistematizada, o ditado americano segundo o qual o preço da liberdade é a eterna vigilância.

\section{REFERÊNCIAS BIBLIOGRÁFICAS}

ACKEL veta documento do PC. O Estado de São Paulo, São Paulo, 30 maio 1984.

ASHEIM, L. Bibliotecas e censura. Revista Brasileira de Biblioteconomia e Documentação, São Paulo, v.13,n.3/4, p.217-222, 1980.

BRASIL. Constituição. 1967. Constituição da República Federativa do Brasil: constituição do Brasil, de 24 de janeiro de 1967, com a redação dada pela Emenda Constitucional n.1, de 17 de outubro de 1969, e as alterações feitas pelas Emendas Constitucionais n.2 a 27. 23.ed. São Paulo: Atlas, 1987. 142p.

BRASIL. Constituição. 1988. Constituição: República Federativa do Brasil. Brasília: Senado Federal-Centro Gráfico, 1988. 292p.

CABALLERO, M. A censura de volta: Ministério da Justiça já tem anteprojeto. Jornal do Brasil, Rio de Janeiro, 11 set. 1984. Caderno B.

CARONE, E. O Estado Novo: 1937-1945. Rio de Janeiro: DIFEL, 1977. 387p. (Corpo e Alma do Brasil).

CENSORES se instalam em TVs e controlam noticiário. Jornal do Brasil, Rio de Janeiro, 24 abr. 1984. 
CENSURA censurada. Veja,São Paulo, 17 nov. 1971.

CENSURA foi quem mais agiu no ministério de Falcão. Jornal do Brasil,Rio de Janeiro, 12 mar. 1979.

CENSURA mutila Roque Santeiro. Veja, São Paulo, 23 out. 1985 .

CENSURA veta Declaração de Independência. Jornal do Brasil, Rio de Janeiro, 4 jul. 1976.

CHARBONNEAU, J.P. Lógica da censura. Folha de São Paulo, São Paulo, 4 mar. 1985. Seção Tendências/ Debates.

COFRE da UnB escondia obras consideradas "subversivas". Boletim da Associação Paulista de Bibliotecários, São Paulo, v.3, n.2, p.3, 1986.

CRUZ, R. Liberalismo, crise e informação: em busca de um fio condutor. Transinformação,Campinas, v.6, n.1/3, p.29-39, jan./dez. 1994.

DIMENSTEIN, G. As armadilhas do poder: bastidores da imprensa. São Paulo: Folha de S.Paulo/Summus, $1990.155 \mathrm{p}$.

ODISCURSO da oposição não foi ao ar. Jornal da Tarde, São Paulo, 24 set. 1973.

DOTTI, R.A. O interesse popular da notícia. Folha de São Paulo, São Paulo, 12 jan. 1993a. Caderno Brasil, p.3.

DOTTI, R.A. Um novo tipo de censura. Folha de São Paulo, São Paulo, 14 jan. 1993b. Caderno Brasil, p.3. É crime publicar documentos do exército? Coojornal,Porto Alegre, abr. 1980, p.26-29.

'ELDORADO' é desobrigada a transmitir programa. O Estado de São Paulo, São Paulo, 9 jan. 1998, p.A13.

ETCHEVERRY, C.A. Judiciário X imprensa: controle judicial não é censura prévia. Disponível siteAjuris (4/11/1996). URL: http://www.ajuris.org.br/div3.html. Consultado em 15 jul.1997.

FANTINI, F. A dona da censura. Isto É, São Paulo, Ano 8, n.417, p.18-23, 19 dez. 1984.

FOLHA se defende das acusações do Planalto. Folha de São Paulo, São Paulo, 2 mar. 1991. Caderno Brasil, p.8.

FORA do ar. Veja,São Paulo, 30 maio 1984.

FREITAS, J. de. Censura política e escrita idem. Folha de São Paulo, São Paulo, 11 jan. 1986.

FUI eu que detive Roque Santeiro: entrevista com o ministro da Justiça Armando Falcão. O Globo, Rio de Janeiro, 10 set. 1985.

GALVEZ, V. Dentel detém fotógrafo da "Folha" e confisca filmes. Folha de São Paulo,São Paulo, 25 abr. 1984a.
GALVEZ, V. Imprensa Nacional nega-se a publicar estatuto do PCB. Folha de São Paulo,São Paulo, 30 maio 1984b.

GONÇALVES, M.A. Os limites da TV. Folha de São Paulo,São Paulo, 24 abr. 1986. p.17.

OGOVERNO mostra um cabrestoà imprensa. Movimento, São Paulo, 15-21 jan. 1979.

IANNI, O. OEstado e a organização da cultura. Encontros com a Civilização Brasileira, São Paulo, n.1, p.216-241, 1978.

A IMPRENSA tem cumprido seu papel de zelar pela liberdade? Disponível siteIgutenberg(11/09/1997). URL: http://www.igutenberg.com.br/ emquest9.htm\# Pérolas da impunidade. Consultado em 25 set. 1997.

JORNALISTAS da Folha depõem em São Paulo. Folha de São Paulo, São Paulo, 2 mar. 1991. Caderno Brasil, p.1.

LEITE, A.M. Direito à honra. Folha de São Paulo, São Paulo, 20 dez. 1997. Caderno Cotidiano, p.10.

LÉNINE, V.I. Obras escolhidas. São Paulo: Alfa-Ômega, 1980. t.2.

LIXO faz Planalto descredenciar repórter de "Veja". Jornal do Brasil, Rio de Janeiro, 26 abr. 1983.

LOUREIRO, U. A censura à informação econômica. Folha de São Paulo, São Paulo, 2 jul. 1978.

LUCAS, C.R. O sistema de informação e o processo de transferência tecnológica. Campinas: PUC-Campinas, 1987. 141p. (Dissertação Mestrado).

LUDWIG anuncia fim da censura e lembra abertura gradual. Jornal do Brasil, Rio de Janeiro, 9 jun. 1978.

MARTINS, I.G. da S. O avanço do retrocesso. Disponível site Radioeldorado. URL: http:// www.radioeldorado.com.br/eldoradoam/telas/ 1.htm. Consultado em 25 set. 1997.

MICROFONES abertos. Veja, São Paulo, p.33-34, 10 jan. 1979.

MISSA proibida. Movimento, São Paulo, 29 jun./5 jul. 1981. p.5.

MINISTÉRIO cerceia imprensa. O Estado de São Paulo, São Paulo, maio 1985.

MORAES, J.L. de. A ética no jornalismo. Cidade Nova, São Paulo, v.38, n.4, p.8-10, abr. 1996.

MOTA, C.G. Cultura e política no Estado Novo: 1937-1945. Encontros com a Civilização Brasileira, São Paulo, n.7, p.87-94, 1979. 
'NP' recorre ao tribunal contra censura. Folha de São Paulo, São Paulo, 12 jan. 1993. Caderno Brasil, p.8.

PELÚCIO, L. Liberdade para quê? A Notícia, São Carlos, 10 ago. 1997. Caderno $\mathrm{N}$, não-paginado.

PEREIRA, A.T. Liberdade de imprensa, abusos, censura e intervenção judiciária: breves reflexões. Disponível site Ajuris (4/11/1996). URL: http:// www.ajuris.org.br/dout_6. html. Consultado em 15 jul. 1997.

PLENÁRIA aprova censura à imprensa. Folha de São Paulo,São Paulo, 8 maio 1986.

PONTES DEMIRANDA. Comentários à constituição de 1946: arts. 129-144. Rio de Janeiro: H. Cahen, 1947. v.3.

RODRIGUES, M.T.M. A Voz do Brasil. Disponível si Radioeldorado. URL: http:// www.radioeldorado.com.br/ eldoradoam/telas/5.htm. Consultado em 25 set. 1997.

SANCHES, P.A. Comitiva de censores "visitou" show. Folha de São Paulo, São Paulo, 3 jul. 1997. Caderno Ilustrada, p.5-3.
TAVARES, J.N. O conceito marxista do Estado: uma introdução. Encontros com a Civilização Brasileira, Sao Paulo, n.7, p.99-110, 1979.

TRÊS anos de resistência. Movimento,São Paulo, 12 jun. 1978.p.13-20. Edição especial: A história da censura prévia em Movimento.

UM nervo exposto. Veja, São Paulo, p.24-25, 7 abr. 1982.

VERGUEIRO, W. de C.S. Os bibliotecários, as bibliotecas e a censura. Boletim da Associação Paulista de Bibliotecários, São Paulo, v.3, n.3, p.2-3, 1986.

VERGUEIRO, W. de C.S. Censura e seleção de materiais em bibliotecas: o despreparo dos bibliotecários brasileiros. Ciência da Informação, Brasília, v.16, n.1,p.21-26, jan./jun. 1987.

VITÓRIA da lei. Veja,São Paulo, 27 ago. 1980.

VOLTA à censura. Folha de São Paulo, São Paulo, 8 maio 1986. Seção Opinião, p.2.

WALD, A. O Estado, a informação e os meios de comunicação. Disponível siteRadioeldorado. URL: http://www.radioeldorado.com.br/eldoradoam/telas/ 9.htm. Consultado em 25 de set. 1997. 